\title{
$\mathrm{Bi}_{1.6} \mathrm{~Pb}_{0.4} \mathrm{Sr}_{2} \mathrm{Ca}_{2} \mathrm{Cu}_{3-x} \mathrm{~V}_{x} \mathrm{O}_{y}$ 体系的超导电性 ${ }^{*}$
}

\author{
卢亚锋 吴晓祖 ${ }^{(1)}$ 周 廉 (1) 董诠健 全天魁 冯 勇(2) \\ (陕西师范大学物理系, 西安 710062; (1)西北有色金属研究院，宝鸡 721014; \\ (2)中国科学技术大学结构中心，合肥 230026)
}

\section{关链词高盜超导体、 $\mathrm{Bi}(\mathrm{Pb}) \mathrm{SrCaCuO}$ 体系、元素替换}

元素替换是探索高温超导电性机理和材料物埋研究的重要途径之一. 由于 $\mathrm{Bi}$ 系组分的 复杂性,因此元素替换的实验研究大量集中在 $\mathrm{Bi}$ 位和 $\mathrm{Bi}_{2} \mathrm{Sr}_{2} \mathrm{Ca}_{1} \mathrm{Cu}_{2} \mathrm{O}_{x}$ 组分的 $\mathrm{Ca}$ 位, $\mathrm{Cu}$ 位 的替代很少. 在 $\mathrm{Bi}_{2} \mathrm{Sr}_{2} \mathrm{Ca}_{1-x} \mathrm{Gd}_{x} \mathrm{Cu}_{2-x} \mathrm{Li}_{x} \mathrm{O}_{8+d}$ 体系中, $\mathrm{Li}^{+}$部分替代 $\mathrm{Cu}^{2+}$ 引起的无序导致 库仑作用的增强, 因而抑制了 $T_{\mathrm{c}}{ }^{\mathrm{d}}$; 在 $\mathrm{Bi}_{1.7} \mathrm{~Pb}_{0.3} \mathrm{Sr}_{2} \mathrm{Ca}_{2}\left(\mathrm{Cu}_{3-x} \mathrm{Sn}_{x}\right)_{1.2} \mathrm{O}$, 体系中的情形也是如

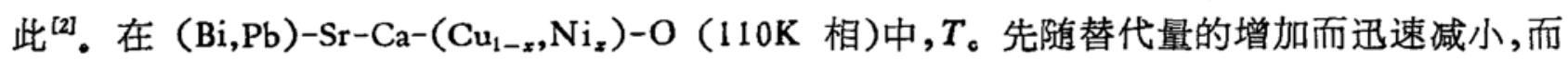
后稳定在约 $90 \mathrm{~K}, T_{\mathrm{c}}$ 的下降被认为是拆对效应所致 ${ }^{[3]}$. 当用过渡元素 $\mathrm{V}$ 替代 $\mathrm{Cu}$ 时, 在 $\mathrm{Bi}_{2} \mathrm{Sr}_{2} \mathrm{Ca}\left(\mathrm{Cu}_{1-s} \mathrm{~V}_{x}\right)_{2} \mathrm{O}_{8}$ 体系中, $T_{c}$ 在 $0 \leqslant x \leqslant 0.05$ 范围内降低了 $5.6 \mathrm{~K}^{[4]}$. Xin 等在 2223 名 义组分中作高价离子掺杂研究时也发现 $\mathrm{V}$ 实际上会进入 $\mathrm{Cu}$ 格位 ${ }^{[]}$. 另外, 利用交流磁化率 曲线研究 $\mathrm{Bi}$ 系超导材料的弱连接行为对于制备高 $J_{\mathrm{o}}$ 体材有重要价值. 作者曾提出了一种 解释 ${ }^{(6)}$, 吴冰青等认为这种所谓 “双台阶” 现象是一种界面效应 ${ }^{[7]}$. 本文报道 $\mathrm{Bi}_{1.6} \mathrm{~Pb}_{0.4} \mathrm{Sr}_{2} \mathrm{Ca}_{2}$ $\mathrm{Cu}_{3-x} \mathrm{~V}_{x} \mathrm{O}$, 体系中 $\mathrm{V}$ 替代 $\mathrm{Cu}$ 对超导电性的影响. 认为 $T_{\mathrm{c}}$ 的抑制主要是 $\mathrm{CuO}_{2}$ 面上无序 引起载流子局域化造成的; 这种材料交流磁化率曲线上的低温区转变台阶主要是由晶粒间非 超导相及 2223 相大倾角界面而形成的弱连接引起的.

\section{1 实 验方法}

采用固相反应法制备了 $\mathrm{Bi}_{1.6} \mathrm{~Pb}_{0.4} \mathrm{Sr}_{2} \mathrm{Ca}_{2} \mathrm{Cu}_{3-x} \mathrm{~V}_{x} \mathrm{O}_{y}(0 \leqslant x \leqslant 0.5)$ 样品. 把适量的 $\mathrm{Bi}_{2} \mathrm{O}_{3}$, $\mathrm{PbO}, \mathrm{SrCO}_{3}, \mathrm{CaCO}_{2}, \mathrm{CuO}$ 和 $\mathrm{V}_{2} \mathrm{O}$, 分析纯粉末充分泥研后于 $800^{\circ} \mathrm{C}$ 预烧 $24 \mathrm{~h}$, 取出重新研磨后 压片, 于空气中 $835^{\circ} \mathrm{C}$ 烧结 $120 \mathrm{~h}$, 然后随炉冷却至室温.

样品的热重及差热分析在杜邦公司生产的热分析仪上完成. 采用直流四引线法测量正常 态电阻率-温度关系. 采用互感法测量交流磁化率. 用 Philips-1700 型 $\mathrm{X}$ 射线衍射仪 $\mathrm{CuK} \alpha$ 辐射测定粉末样品的衍射谱. 用 SEM (S-570)、EDAX (PB9900) 上作样品形貌观察及成分 的能谱分析.

\section{2 结果和讨论}

样品的 DTA 曲线表明, $\mathrm{V}_{2} \mathrm{O}_{5}$ 的加入使体系部分熔化温度最低降至 $843^{\circ} \mathrm{C}$, 因此选择烧 结温度为 $835^{\circ} \mathrm{C}$. 图 1 给出样品的室温 $\mathrm{X}$ 射线衍射谱. 从图 1 可以看出, 含 $\mathrm{V}$ 体系是一多相

* 国家超导中心基金资助项目. 
混合体系，其中包括超导的 2223 相、2212 相及 2201 相; $\mathrm{Ca}_{2} \mathrm{PbO}_{4} ; \mathrm{Ca}_{2} \mathrm{CuO}_{3} ; \mathrm{Sr}-\mathrm{V}$ 或 $\mathrm{V}-\mathrm{Cu}$ 复合氧化物和其它杂相. 若不计非超导相, 以公式

$$
\mathrm{V} \%=\frac{\mathrm{I}_{(2223) \text { 相(0010)或 }} \mathrm{I}_{(2212) \text { 淿(008) }} \text { 或 } \mathrm{I}_{(2201) \text { 相(006) }}}{\mathrm{I}_{(2223) \text { 相(0010) }}+\mathrm{I}_{(2212) \text { 相(008) }}+\mathrm{I}_{(2201) \text { 相(006) }}} \times 100 \%
$$

来估算三种超导相的相对含量, 则可以得到: 随 $x$ 增加 2223 相的相对含量渐增, $x=0.4$ 时最 高为 $58 \%$ 之后又降低;2212 相含量变化趋势相 反; 而 2201 相含量单调上升. 所有非超导相的 衍射峰强度随 $x$ 增大洏加强. 计算表明, 随着 $\boldsymbol{x}$ 增加, $110 \mathrm{~K}$ 相晶格常数 $c$ 值系统减小, 说明 $\mathrm{V}$ 至少部分地进入了 2223 相晶格. 由于 $\mathrm{V}^{5+}$ 离子半径 $(0.59 \AA)$ 小于 $\mathrm{Cu}^{2+}$ 离子半径 $(0.72$ $\AA$ ), 因此 $\mathrm{V}$ 会进入晶格替代 $\mathrm{Cu}$ 位. 用扫描 电镜和能谱分析对 $x=0.4$ 样品的微区成分分 析结果表明, 在典型的片状 2223 相晶粒中, V 分布是均匀的, 晶粒的平均成分接近理想成 分.

图 2 给出样品的交流磁化率曲线, 并由此 确定 2223 相的超导抗磁性转变温度 $T_{\mathrm{c}} . T_{\mathrm{c}}$ 随 $x$ 变化曲线见图 3, 当 $x$ 增加时,2223 相的超导 转变温度逐渐下降. 这一结果也支持 $\mathrm{V}$ 的确替
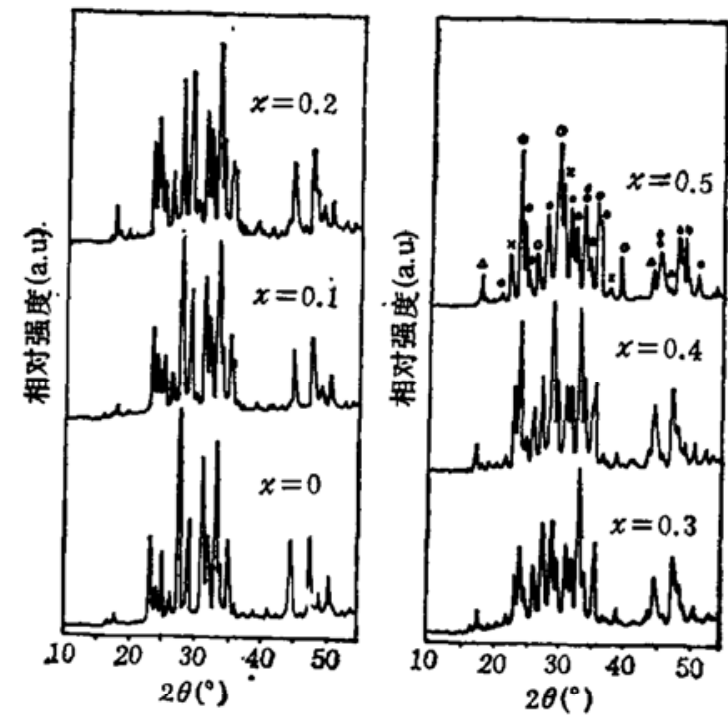

图 1 样品的室温 $\mathrm{X}$ 射线衍射谱 $O$ 为 2223 相, -为 2212 相, $X$ 为 2201 相, $\Delta$ 为杂相

代 $\mathrm{Cu}$ 并对超导电性产生了某种影响. 假定体系氧含量不随 $x$ 而变化, 那么 $\mathrm{V}^{5+}$ 离子替代 $\mathrm{Cu}^{2+}$ 离子将造成 $\mathrm{CuO}_{2}$ 面上的 $\mathrm{Cu}$ 空位, 这些空位会使部分可移动载流子局域化, 降低载 流子浓度, 从而抑制 J $T_{\mathrm{c}}$ 。

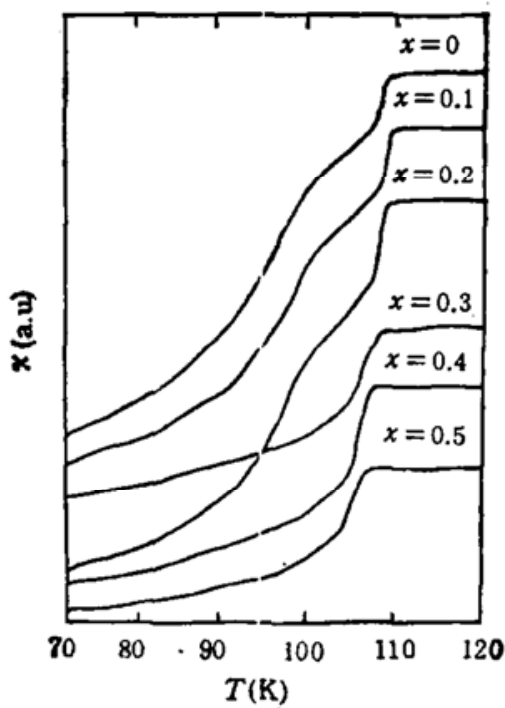

图 2 样品的交流磁化率曲线

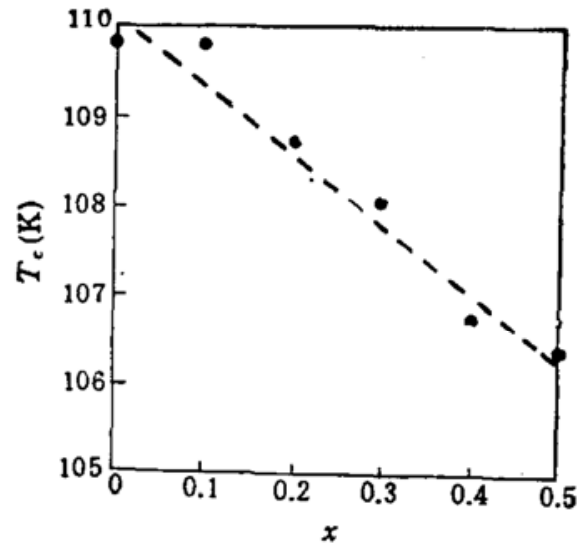

图 3 体系的 $T_{c}$ 与 $x$ 的关系曲线

图 $2 \chi-T$ 曲线上的低温区转变台阶有明显的变化趋势: 随 $x$ 增加该台阶逐渐向低温方 向移动, 在 $x$ 从 0.3 到 0.5 范围内消失即 $77 \mathrm{~K}$ 以上仅表现 2223 相超导抗磁性转变. 对照样品 
$\mathrm{XRD}$ 谱, 尽管 $x=0.4$ 时 2223 相含量最高, 但该台阶仍低于 $77 \mathrm{~K}$. 相反该转变台阶的变化 与非超导相含量变化对应. 考虑到 2212 相的 $T_{\mathrm{c}}$ 随氧含量增加明显减小, 那么在本实验条 件下, 2212 相的 $T$ 。会低于 77K. 因此我们认为 $\mathrm{Bi}$ 系的这类低温区转变台阶主要是由弱连 接引起的, 在 $\mathrm{Bi}_{1.6} \mathrm{~Pb}_{0.4} \mathrm{Sr}_{2} \mathrm{Ca}_{2} \mathrm{Cu}_{3-x} \mathrm{~V}_{x} \mathrm{O}$, 体系中, 弱连接主要是由作为晶粒间界物质的非超导 相和 2223 相大倾角界面形成的.

该体系从 $77 \mathrm{~K}$ 到室温范围内的电阻率-温度关系曲线表明, 在 $x$ 从 0 到 0.4 范围内其正 常态电阻-温度关系一直保持金属行为, $x=0$ 时 $T_{\mathrm{co}}=106 \mathrm{~K}$ 为最高, 随 $x$ 增加 $T_{\mathrm{co}}$ 减小, 直至 $x=0.4$ 时 $R-T$ 曲线虽然在 $110 \mathrm{~K}$ 附近有电阻突降但 $77 \mathrm{~K}$ 以上未出现零电阻. 在 $x=0.5$ 开始出现半导体行为, 这可能是由某些杂相造成的.

总之, 用过渡元素 V 替代 $\mathrm{Cu}$ 对 $\mathrm{Bi}$ 系超导电性产生了系统影响, 2223 相 $T_{\mathrm{c}}$ 随 $x$ 增大 下降了 3.4K. 低温区抗磁性转变台阶主要是由弱耦合引起的. 进一步工作仍在进行.

\section{参文嗝}

[1] Jayaram, B. et al., Phys. Rev., B, 1991, 43: 10589.

[2] Nkum, R. K. et al., Physica, C, 1992, 190: 465.

[3] Natsuki Mori et al., Phys. Rev., B, 1992, 45:10633.

[4] Lonnberg, B. et al., Physica, C, 1992, 191:147.

[5] Xin, Y. et al., Physica, C, 1991, 176:179.

[6] 卢亚锋等,低温物理学报, 1992,(2): 97.

[7] 吴冰青等,低温物理学报, 1992,(4): 276. 